\title{
REVIEW
}

\section{Considerations in the management of hypoxemic respiratory failure and persistent pulmonary hypertension in term and late preterm neonates}

\author{
S Lakshminrusimha ${ }^{1}$, GG Konduri ${ }^{2}$ and RH Steinhorn ${ }^{3}$
}

\begin{abstract}
Recent advances in our understanding of neonatal pulmonary circulation and the underlying pathophysiology of hypoxemic respiratory failure (HRF)/persistent pulmonary hypertension of the newborn (PPHN) have resulted in more effective management strategies. Results from animal studies demonstrate that low alveolar oxygen tension $\left(\mathrm{PAO}_{2}\right)$ causes hypoxic pulmonary vasoconstriction, whereas an increase in oxygen tension to normoxic levels (preductal arterial partial pressure of oxygen $\left(\mathrm{PaO}_{2}\right)$ between 60 and $80 \mathrm{~mm} \mathrm{Hg}$ and/or preductal peripheral capillary oxygen saturation between 90\% and 97\%) results in effective pulmonary vasodilation. Hyperoxia (preductal $\mathrm{PaO}_{2}>80 \mathrm{~mm} \mathrm{Hg}$ ) does not cause further pulmonary vasodilation, and oxygen toxicity may occur when high concentrations of inspired oxygen are used. It is therefore important to avoid both hypoxemia and hyperoxemia in the management of PPHN. In addition to oxygen supplementation, therapeutic strategies used to manage HRF/ PPHN in term and late preterm neonates may include lung recruitment with optimal mean airway pressure and surfactant, inhaled and intravenous vasodilators and 'inodilators'. Clinical evidence suggests that administration of surfactant or inhaled nitric oxide (iNO) therapy at a lower acuity of illness can decrease the risk of extracorporeal membrane oxygenation/death, progression of HRF and duration of hospital stay. Milrinone may be beneficial as an inodilator and may have specific benefits following prolonged exposure to iNO plus oxygen owing to inhibition of phosphodiesterase (PDE)-3A. Additionally, sildenafil, and, in selected cases, hydrocortisone may be appropriate options after hyperoxia and oxidative stress owing to their effects on PDE-5 activity and expression. Continued investigation into these and other interventions is needed to optimize treatment and improve outcomes.
\end{abstract}

Journal of Perinatology (2016) 36, S12-S19; doi:10.1038/jp.2016.44

\section{INTRODUCTION}

Term and late preterm newborns with respiratory failure requiring mechanical ventilation represent a high-risk population with significant morbidity and mortality. ${ }^{1}$ Respiratory failure at this gestational age is frequently complicated by persistent pulmonary hypertension of the newborn (PPHN). ${ }^{2,3}$ PPHN occurs in diverse settings and encompasses a wide spectrum of diseases, including but not limited to respiratory distress syndrome, meconium aspiration syndrome (MAS), pneumonia, sepsis and primary pulmonary hypertension (Figure 1). ${ }^{2,3}$ PPHN reflects the failure of the pulmonary vasculature to relax at birth, which results in increased pulmonary arterial pressure and pulmonary vascular resistance (PVR), leading to right-to-left shunting of deoxygenated blood from the pulmonary to systemic circulation (Figure 1)., PPHN is a neonatal emergency that requires timely and precise intervention to prevent severe hypoxia and short- and long-term morbidities. Appropriate clinical management of PPHN in term and late preterm newborns requires a full understanding of the pathogenesis of PPHN and recognition that pulmonary circulation differs from systemic circulation in structure, function and regulation (for example, hypoxia causes pulmonary vasoconstriction but dilates the systemic circulation).

This article discusses translational science and current challenges, as well as best practices, in the management of hypoxemic respiratory failure (HRF) and PPHN in term and late preterm neonates. It is part of a series summarizing presentations and discussions from a roundtable discussion that focused on HRF in neonates (see the Introduction to this issue).

\section{INHALED THERAPY AND VENTILATION}

Optimizing oxygenation: avoid both hypoxemia and hyperoxemia Ensuring adequate oxygen delivery to the brain and other tissues represents the mainstay of PPHN therapy via therapeutic modalities, such as oxygen supplementation, mechanical ventilation and inhaled nitric oxide (iNO). Oxygen delivery is dependent on blood flow and arterial oxygen content $\left(\mathrm{CaO}_{2}\right)$ (Figure 1).

\section{Oxygen use at birth}

During the intrauterine period, the fetus is in a state of physiological pulmonary hypertension, partly secondary to relative hypoxemia. At birth, following ventilation of lungs with air, a rise in oxygen tension contributes to rapid pulmonary vasodilation. In normal term neonatal lambs, use of $21 \%$ oxygen during initial ventilation led to a decrease in PVR in the immediate postnatal period. ${ }^{6}$ Although initial ventilation with $100 \%$ oxygen marginally enhanced the decrease in PVR at birth, it also impaired pulmonary vasodilation in response to a subsequent exposure to iNO.

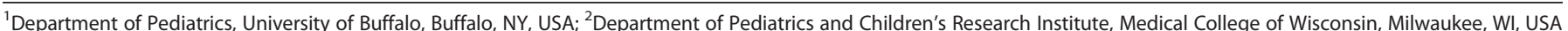

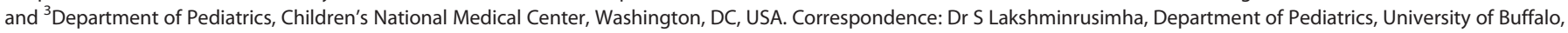
219 Bryant Street, Buffalo, NY 14222, USA.

E-mail: slakshmi@buffalo.edu

Received 15 October 2015; revised 10 February 2016; accepted 16 February 2016 


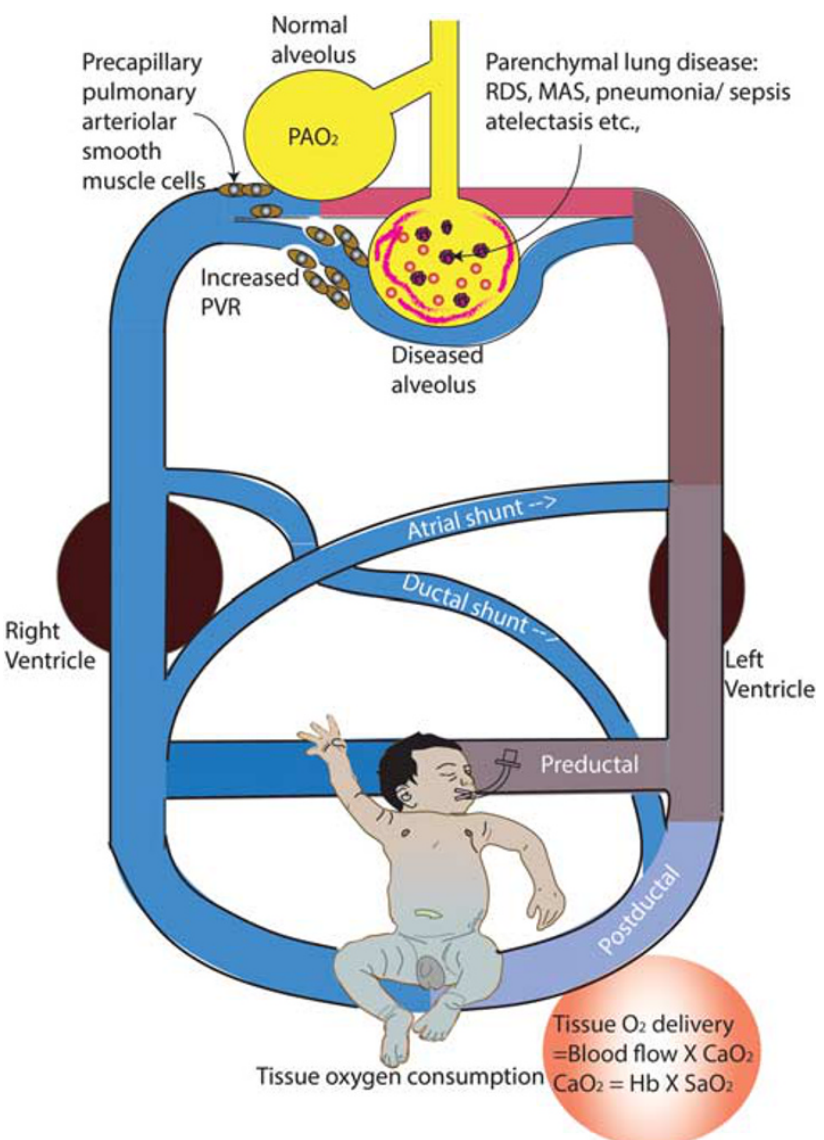

Figure 1. Pathophysiology of persistent pulmonary hypertension of the newborn (PPHN)-precapillary pulmonary arteriolar smooth muscle cells are considered to be the primary oxygen sensors in the pulmonary vasculature. Their partial pressure of oxygen $\left(\mathrm{PO}_{2}\right)$ is mainly regulated by alveolar oxygen tension $\left(\mathrm{PAO}_{2}\right)$. In PPHN, increased pulmonary vasoconstriction secondary to various causes, including parenchymal lung disease such as respiratory distress syndrome (RDS), meconium aspiration syndrome (MAS) and pneumonia/sepsis, results in increased pulmonary vascular resistance (PVR). This leads to right ventricular hypertrophy and right-toleft shunt across the patent foramen ovale (atrial shunt) and ductus arteriosus (ductal shunt) leading to hypoxemia. A ductal shunt results in differential cyanosis with preductal oxygen levels higher than postductal oxygen levels. The goal of therapy in hypoxemic respiratory failure (HRF) and PPHN is to optimize tissue oxygen delivery. (Copyright: Dr Lakshminrusimha, $\mathrm{Dr}$ Konduri and Dr Steinhorn). $\mathrm{CaO}_{2}$, arterial oxygen concentration; $\mathrm{O}_{2}$, oxygen; $\mathrm{SaO}_{2}$, arterial oxygen saturation.

Similar results were seen in a neonatal lamb model of PPHN with remodeled pulmonary circulation induced by antenatal ligation of the ductus arteriosus ${ }^{7}$ (Figure 2) and in a neonatal lamb model of acute pulmonary hypertension secondary to perinatal asphyxia. ${ }^{8}$ These studies suggest that, while high concentrations of inspired oxygen may induce short-term pulmonary vasodilation, they may also impair subsequent vasodilator response to iNO. The mechanism of hyperoxiainduced impairment of NO-mediated vasodilation is most likely related to inactivation of $\mathrm{NO}$ by superoxide anions and/or superoxide anion-mediated enhancement of cyclic guanosine monophosphate (cGMP)-specific phosphodiesterase (PDE-5) activity (see next section). These findings support the recommendation of the Neonatal Resuscitation Program to use $21 \%$ oxygen for the initial resuscitation of term neonates. ${ }^{9,10}$
Optimal oxygenation during management of a neonate with HRF in the neonatal intensive care unit

It has been recognized for some time that alveolar hypoxia and hypoxemia increase PVR and contribute to the pathophysiology of PPHN. PVR is regulated predominantly by pulmonary arterial smooth muscle cells (PASMCs) in small resistance precapillary pulmonary arterioles (Figure 1). The oxygen tension in these PASMCs is determined by alveolar oxygen tension $\left(\mathrm{PAO}_{2}\right)$ and pulmonary arterial (or mixed venous) partial pressure of oxygen, although $\mathrm{PAO}_{2}$ is considered to be the more important factor. $^{11}$

In clinical practice, preductal arterial partial pressure of oxygen $\left(\mathrm{PaO}_{2}\right)$ is measured and used to calculate $\mathrm{PAO}_{2}$. The relationship between PVR and $\mathrm{PaO}_{2}$ was first described in a study of healthy newborn calves, which found a precipitous increase in PVR as the $\mathrm{PaO}_{2}$ fell below 45 to $50 \mathrm{~mm} \mathrm{Hg}{ }^{12}$ A similar relationship between $\mathrm{PaO}_{2}$ and PVR was later described in an ovine model of PPHN. ${ }^{7}$ Healthy control lambs in this study had an acute increase in PVR with preductal $\mathrm{PaO}_{2}<52.5 \mathrm{~mm} \mathrm{Hg}$ (Figure 3a). In PPHN lambs, hypoxic vasoconstriction was greatly exaggerated with two PVR change points: severe hypoxemia with $\mathrm{PaO}_{2}$ $<13.9 \mathrm{~mm} \mathrm{Hg}$ resulted in a steep increase in PVR (up to $6 \mathrm{~mm} \mathrm{Hg} / \mathrm{mL} / \mathrm{kg} / \mathrm{min}$ ), whereas resistance declined more gradually at $\mathrm{PaO}_{2}>59.6 \mathrm{~mm} \mathrm{Hg}$ (Figure 3b). Within clinically relevant ranges of preductal oxygen saturations ( $80 \%$ to $100 \%)$, PVR increased below capillary oxygen saturation $\left(\mathrm{SpO}_{2}\right)$ of $85 \%$ and also as oxygen saturation exceeded 98\% (Figure 3d). Similar change points were observed in acute PPHN induced by perinatal asphyxia and MAS (Figure 3c). Moreover, in both groups, an increase from $50 \%$ to $100 \%$ inspired $\mathrm{O}_{2}$ did not produce any further decrease in PA pressure or PVR. ${ }^{7}$ These observations suggest that the lowest PVR can be maintained with preductal peripheral $\mathrm{SpO}_{2}$ in the $90 \%$ to $97 \%$ range with preductal $\mathrm{PaO}_{2}$ between 60 to $80 \mathrm{~mm} \mathrm{Hg}$ in these newborn sheep models (Figure $3 \mathrm{~d}$ ).

Findings from these ovine models have clinical relevance to the management of PPHN, as traditional practice often involved hyperoxic ventilation during the acute phase. Such an approach has not been shown to produce persistent clinical benefit in PVR, and the animal studies suggest that this approach paradoxically impairs the subsequent response to iNO.

The mechanisms underlying the hemodynamic effects of hyperoxemia reflect, in part, increased oxidative stress (Figure 4). Ventilation with $100 \%$ oxygen promotes formation of reactive oxygen species (ROS), such as superoxide anions that enhance vasoconstriction in the neonatal pulmonary circulation, ${ }^{13-15}$ and inactivate NO through formation of peroxynitrite. ${ }^{15-18}$ In addition, ROS decrease endothelial nitric oxide synthase activity and soluble guanylyl cyclase activity resulting in reduced cGMP levels ${ }^{19}$ with consequent vasoconstrictor effects. Decreased responsiveness to iNO is reflected in decreased intracellular cGMP response as well as increased PDE-5 cGMP-hydrolytic activity.

The role of ROS in pulmonary vasoconstriction is further supported by demonstration that activation of xanthine oxidase produces acute pulmonary vasoconstriction. ${ }^{20}$ An increase in superoxide anion production has been reported following ventilation of PPHN lambs with $100 \%$ oxygen, which could be reversed by administration of superoxide dismutase. ${ }^{15,21}$ Superoxide dismutase also improved oxygenation, suggesting that ROS formation impairs vasodilation to endothelium-independent agents, such as NO.

Overall, the evidence from animal models indicates that hypoxia causes pulmonary vasoconstriction and normoxia results in pulmonary vasodilation. However, hyperoxia (especially when the fraction of inspired oxygen $\left(\mathrm{FiO}_{2}\right)$ exceeds 0.5 , and $\mathrm{PaO}_{2}$ exceeds 80 to $100 \mathrm{~mm} \mathrm{Hg}$ ) does not cause further pulmonary vasodilation. Hyperoxemia promotes ROS formation and interferes with the function of various enzymes of the NO pathway and reduces CGMP 


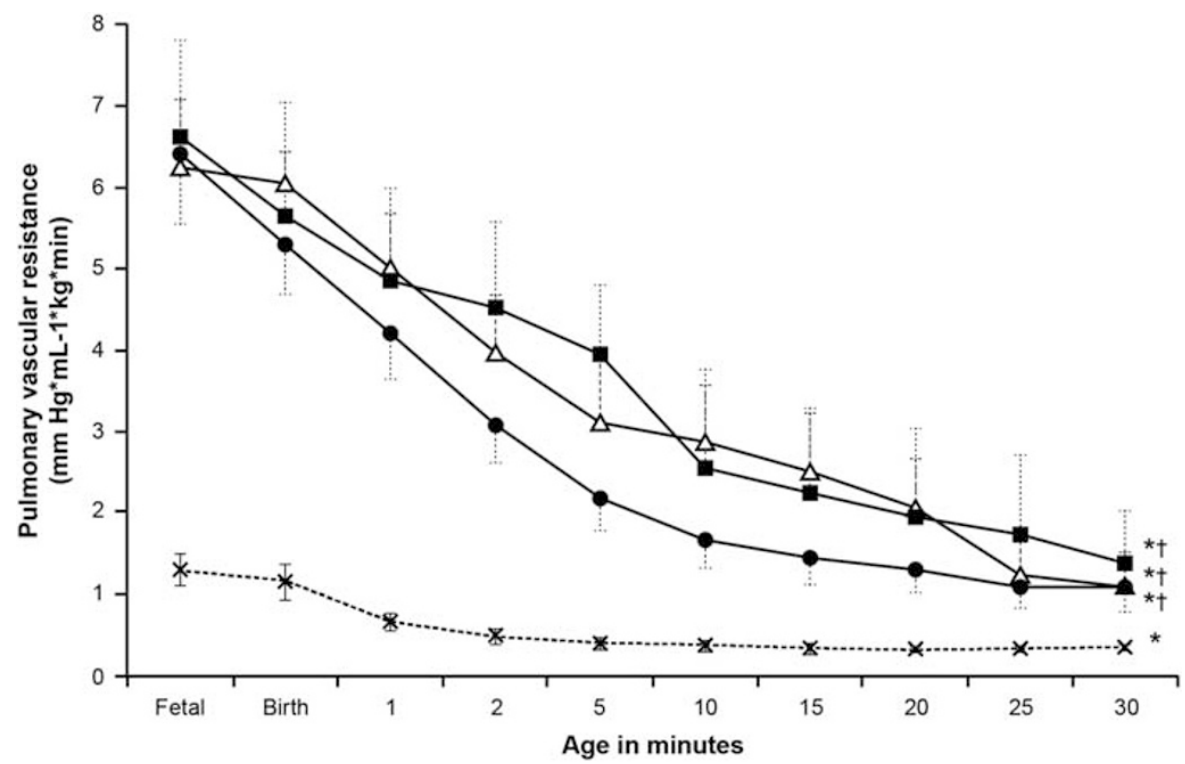

Figure 2. Changes in pulmonary vascular resistance (PVR) (mean \pm s.e.m.) during fetal life, at birth and during the first 30 min of life in persistent pulmonary hypertension of the newborn (PPHN) lambs ventilated with $21 \%$ (black squares), $50 \%$ (white triangles) or $100 \% \mathrm{O}_{2}$ (gray circles) ( $n=6$ each). Similar changes in PVR in four control twin lambs without PPHN ventilated with air are shown for comparison (dashed line). ( ${ }^{*} P<0.05$ by analysis of variance (ANOVA) over time; ${ }^{\dagger} P<0.05$ compared with control by repeated-measures ANOVA). Adapted with permission from Lakshminrusimha et al. ${ }^{7}$

formation (Figure 4). Therefore, avoiding hyperoxemia is potentially as important as avoiding hypoxemia in the management of PPHN. Clinicians should recognize that oxygen is a drug and should be used accordingly in the therapeutic context taking into account potential benefits as well as side effects.

Relationship between $\mathrm{pH}, \mathrm{PaO}_{2}$ and pulmonary vascular response to hypoxia

Early studies in animal models showed that lower pH exaggerates the pressor response to hypoxia (vasoconstriction and increased PVR). ${ }^{12}$ An acceptable $\mathrm{PaO}_{2}$ range, which avoids an hypoxic vasoconstrictor response, is dependent on the acid-base status. Therefore, avoiding acidosis may offer some protection against pulmonary vasoconstriction in response to hypoxia. There is a tendency in clinical practice, however, to compartmentalize $\mathrm{pH}$ and $\mathrm{PaO}_{2}$ using different ventilator controls, which artificially separates these two inter-related parameters. Maintaining arterial $\mathrm{pH} \geqslant 7.3$ appears to reduce the intensity of hypoxic pulmonary vasoconstriction. ${ }^{12}$ There have been many advances in the understanding of mechanisms underlying changes in minute ventilation in response to $\mathrm{PaO}_{2}$ and $\mathrm{pH}$ targets (such as tachypnea in response to hypoxia or hypercarbia). However, the endogenous compensatory mechanisms that determine optimal $\mathrm{PaO}_{2}$ or oxygen saturation still need to be defined (that is, what mechanisms, such as increased cardiac output, allow the newborn to establish appropriate $\mathrm{PaO}_{2}$ target set points in the presence of low $\mathrm{CaO}_{2}$ ).

\section{BENEFITS OF EARLIER INTERVENTION}

Inhaled nitric oxide

Ventilator- and hyperoxia-induced changes in the pulmonary vasculature are seen very early at the subcellular and gene expression levels. Supporting evidence has been derived from analysis of pulmonary artery endothelial cells and lung homogenates isolated from PPHN and control lambs. These samples showed that mitochondrial electron transport chain complex proteins levels are decreased in PPHN, suggesting a disruption in energy metabolism. ${ }^{22,23}$ Furthermore, there was a drastic reduction in the mitochondrial complex proteins when PPHN lambs were ventilated with $100 \%$ oxygen, indicating that mitochondria were undergoing injury and disappearing from the lung. In contrast, preservation of mitochondria and increase in electron transport chain complex proteins occurred in PPHN lambs weaned to a $\mathrm{FiO}_{2}$ target range and treated with iNO. These findings provide a theoretical rationale for early intervention with iNO (ameliorating deleterious subcellular changes), which could translate into clinical benefits. Initiating therapy before alveolar atelectasis from lung disease or ventilator-induced barotrauma or oxygen toxicity could potentially lessen the lung injury with consequent reduction in the duration of respiratory support and/ or length of hospital stay.

Initial clinical trials of iNO for HRF enrolled newborns with advanced respiratory failure, with many of them already meeting extracorporeal membrane oxygenation (ECMO) criteria at the time of enrollment and randomization (oxygenation index $(\mathrm{OI})>40) .{ }^{24-26}$ Although the response to iNO was consistently favorable, many newborns who were critically ill with severe lung disease and vascular dysfunction were unresponsive to therapy.

Results from later trials suggested the advantages of introducing this intervention in infants with moderate PPHN. ${ }^{27-29}$ For example, the Franco-Belgium Collaborative NO trial randomized neonates to early iNO or control ventilation therapy without iNO, stratified by gestation age ( $<33$ or $\geqslant 33$ weeks). In 107 term and late preterm infants with moderate respiratory failure (median OI 25.9), iNO use led to a decrease in $\mathrm{Ol}$ at $2 \mathrm{~h}$, the primary endpoint. ${ }^{27}$ Although methodologically limited, analyses of data from this cohort also suggested that babies assigned to early iNO therapy spent fewer days on mechanical ventilation and less time in the neonatal intensive care unit. Other findings were not significant.

A trial conducted in Chile in a setting where ECMO was not available randomly assigned 56 newborns with moderate respiratory failure (OI 10 to 30 ) at $\leqslant 48 \mathrm{~h}$ after birth to early iNO or conventional mechanical ventilation with oxygen. ${ }^{28}$ Newborns in the control group who reached $\mathrm{Ol}>40$ were treated with iNO. Respiratory variables at baseline were similar, including $\mathrm{FiO}_{2}$ and 
a Control term lambs - normal pulmonary vasculature

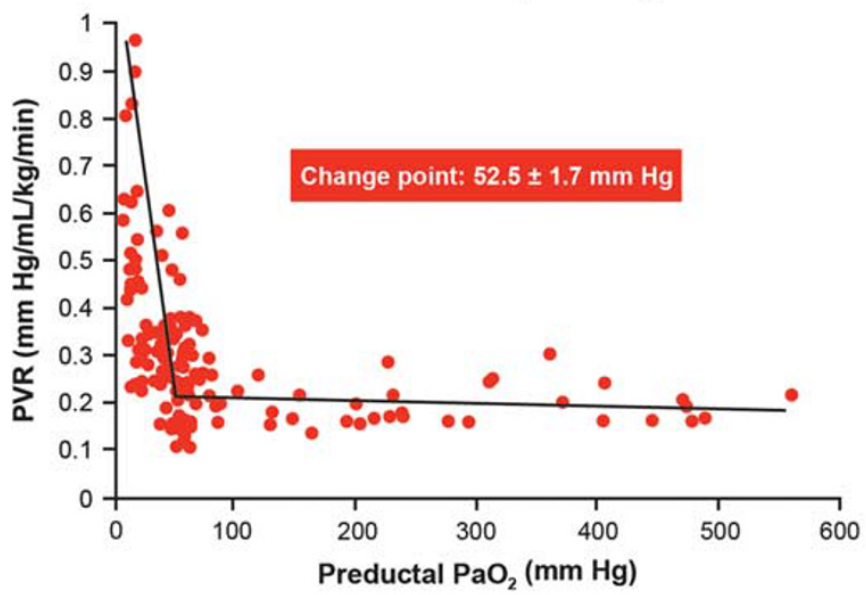

C

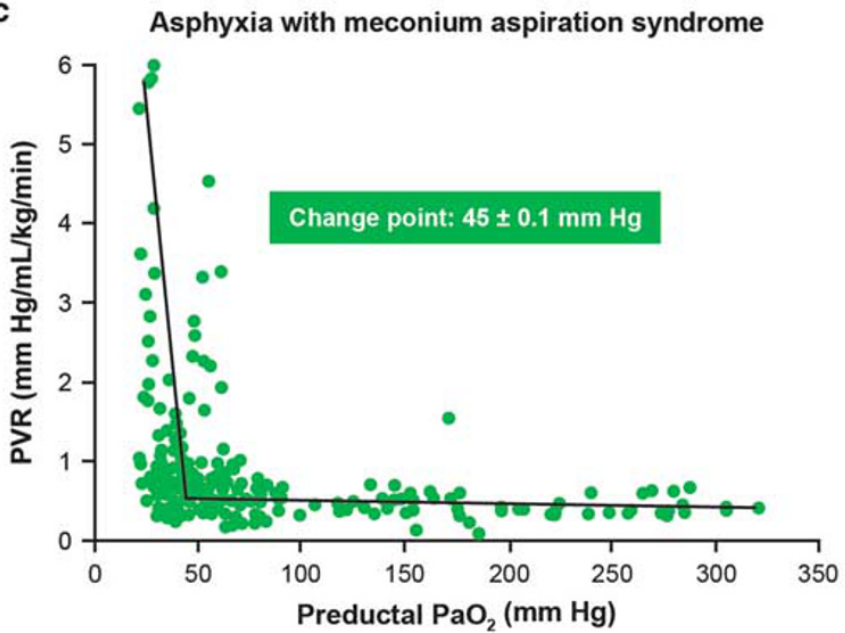

b

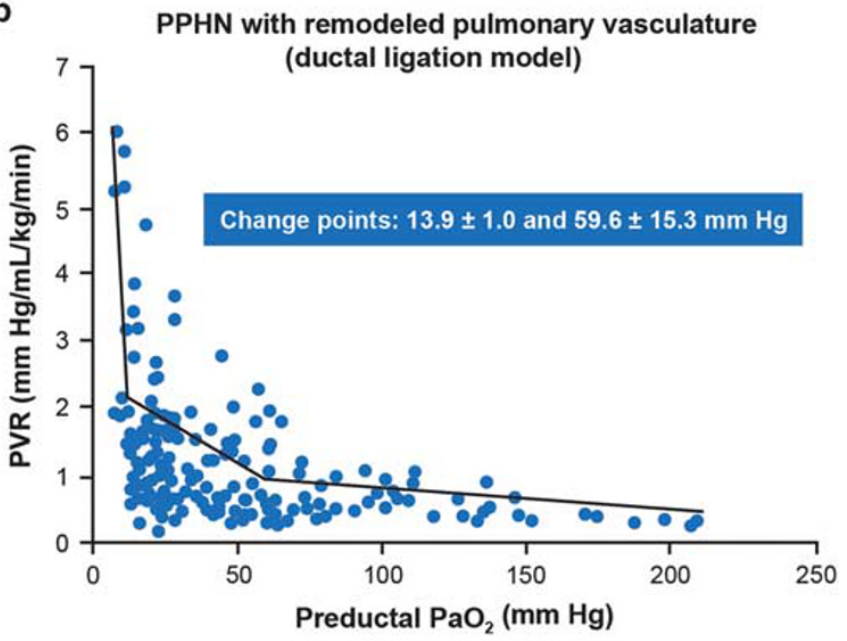

d

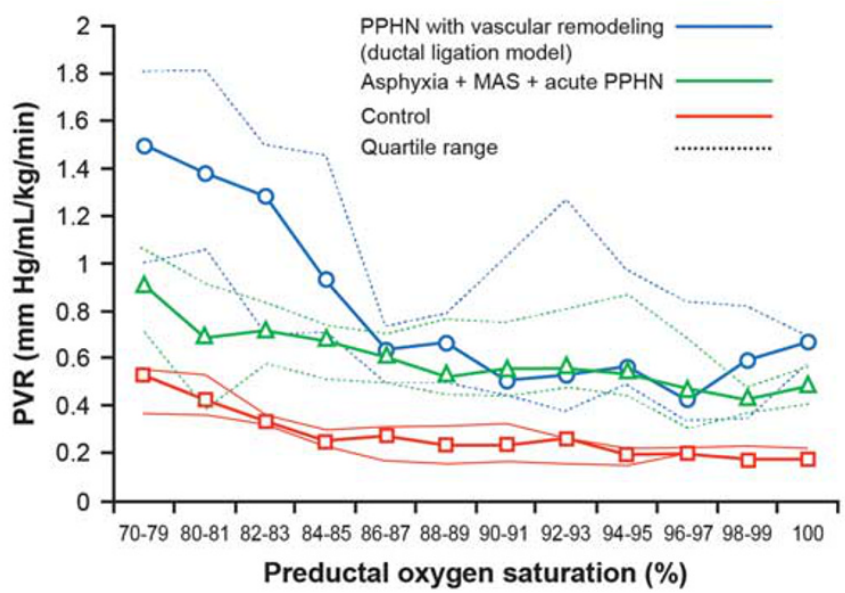

Figure 3. Scatterplots showing pulmonary vascular resistance (PVR) and arterial partial pressure of oxygen $\left(\mathrm{PaO}_{2}\right)$ in control (a), persistent pulmonary hypertension of the newborn (PPHN) with vascular remodeling (b) and asphyxia+meconium aspiration lambs (c). The two regression lines for the control lambs demonstrate a change point of $52.5 \mathrm{~mm} \mathrm{Hg}$ of $\mathrm{PaO}_{2}$. The three regression lines for the PPHN lambs correspond to mean $\mathrm{PaO}_{2}$ change points of $13.9 \pm 1$ and $59.6 \pm 15.3 \mathrm{~mm} \mathrm{Hg}$. The two regression lines in lambs with meconium aspiration demonstrate $\mathrm{a} \mathrm{PaO}_{2}$ change point of $45 \pm 0.1 \mathrm{~mm} \mathrm{Hg}$. Panel (d) demonstrates the median and inter-quartile range (dashed lines) of PVR plotted against a clinically relevant range of oxygen saturations (70\% to $100 \%$ ) in control (a) and PPHN with remodeled pulmonary vasculature induced by antenatal ductal ligation (b) and acute PPHN induced by asphyxia and meconium aspiration (c) in lambs. Adapted and modified with permission from Lakshminrusimha et al. ${ }^{7}$ MAS, meconium aspiration syndrome.

OI. The OI decreased in the early iNO group from 22 at baseline to 19 at $4 \mathrm{~h}(P<0.05$ vs baseline) and remained lower at all subsequent time points. In contrast, Ol increased in the control group and remained significantly higher $(P<0.01$ vs early iNO group) during the first $48 \mathrm{~h}$ of the study (Figure 5). ${ }^{28}$ Significantly fewer newborns receiving early iNO (25\%) compared with conventional therapy (61\%) developed $\mathrm{Ol}>40$, defined as the primary endpoint of treatment failure $(P<0.05)$, although mortality, days of mechanical ventilation and rates of chronic lung disease did not differ. Along with improved oxygenation, newborns on early iNO had a reduction in duration of oxygen exposure $(P<0.03$ vs controls). These results with early iNO are consistent with a potential decrease in disease progression in newborns with moderate respiratory failure.

Additional evidence for the benefit of early intervention can be derived from the multicenter Neonatal Inhaled Nitric Oxide Study Group trial that randomized 299 term and late preterm neonates (gestational age $\geqslant 34$ weeks) with moderate respiratory failure (Ol 15 to 25 ) to early iNO or placebo. ${ }^{29}$ The study population had a wide variety of diagnoses (primary PPHN, MAS, respiratory distress syndrome, pneumonia/sepsis, lung hypoplasia), and all study infants (including controls) were eligible to receive standard iNO therapy if HRF progressed to $\mathrm{OI} \geqslant 25$. The trial failed to show a difference between the early iNO group and the control group for the primary outcome of ECMO/death $(16.7 \%$ vs $19.5 \%$, respectively; $P=\mathrm{NS}$ ). However, the overall incidence of ECMO/death in this trial was noticeably lower than that observed in earlier randomized trials in newborns with more advanced disease. ${ }^{29}$ In addition, there was limited separation between the two study groups as the mean $\mathrm{Ol}$ at the time of enrollment in the trial was nearly 20 and control infants were eligible to receive iNO at an Ol of 25. Nevertheless, arterial oxygen tension increased by $>20 \mathrm{~mm} \mathrm{Hg}$ in $73 \%$ of early iNO neonates compared with $37 \%$ of control neonates $(P<0.001){ }^{29}$ Thus infants earlier in the course of respiratory failure responded favorably to iNO although one-third remained unresponsive.

In the Konduri et al. trial, a post-hoc analysis found that $\mathrm{Ol}<20$ $(P=0.031)$ and prior surfactant use $(P=0.008)$ were significantly associated with decreased risk of ECMO/death. ${ }^{30}$ Irrespective of exposure to iNO, use of surfactant therapy prior to target Ol of 15 
to 25 in the infants with parenchymal lung disease was associated with a striking threefold reduction in the risk of this endpoint $(P<0.001)$. The decrease was primarily observed in infants with MAS $(P=0.04)$, respiratory distress syndrome $(P=0.04)$ or pneumonia/sepsis $(P=0.03)$ and not in infants with PPHN $(P=0.43)$. In the early iNO group, exposure to iNO at $\mathrm{Ol}<20$ decreased ECMO/

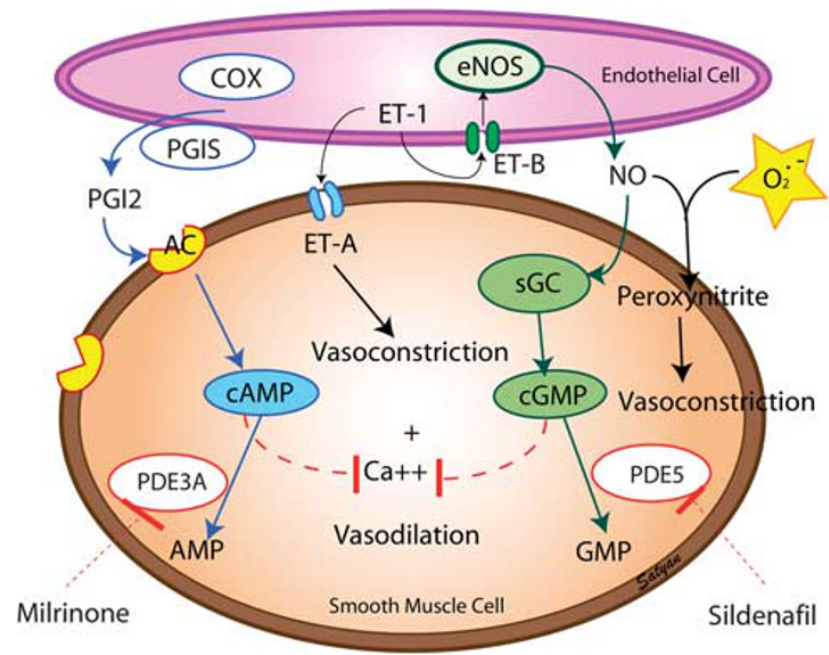

Figure 4. Alterations in biochemical and enzyme pathways in persistent pulmonary hypertension of the newborn (PPHN) and effect of hyperoxia on these pathways. See text for details (Copyright: Dr Lakshminrusimha). ${ }^{4,5}$ AC, adenylate cyclase; AMP, adenosine monophosphate; $\mathrm{Ca}$, calcium; cAMP, cyclic adenosine monophosphate; cGMP, cyclic guanosine monophosphate; COX, cyclooxygenase; eNOS, endothelial nitric oxide synthase; ET-1, endothelin-1; ET-A, endothelin-A; ET-B, endothelin-B; GMP, guanosine monophosphate; NO, nitric oxide; $\mathrm{O}_{2}$, oxygen; PDE3A, phosphodiesterase 3A; PDE5, phosphodiesterase 5; PGIS, prostacyclin synthase; PGI2, prostaglandin I2; SGC, soluble guanylyl cyclase. death (odds ratio 0.25 , confidence interval $\mathrm{Cl} 0.08$ to $0.67 ; P=0.01$ ) compared with infants at an $\mathrm{Ol} 20$ to 25 , suggesting that intervention with iNO was more effective at $\mathrm{Ol}<20$.

Although this was a post-hoc analysis, the results suggest that early use of surfactant and iNO in moderate respiratory failure could lead to improved outcomes. Early treatment with iNO at an $\mathrm{Ol}<20$ was also associated with decreased length of stay, compared with control infants who presented at the same OI and received standard iNO at $\mathrm{Ol}>25$ (18 vs 27 days). Supplementing these findings, a pharmacoeconomic analysis of this population suggested that early use of iNO (at Ol $\geqslant 15$ to $<20$ ) was associated with lower total cost of care relative to standard iNO ( $\$ 88518 \pm 7574$ vs $\$ 92581 \pm 9664$ ) based on costs of hospital care, iNO and ECMO at the time of analysis. ${ }^{31}$

\section{Surfactant}

Randomized clinical trials have confirmed that surfactant therapy is effective in reducing the immediate need for respiratory support and improving clinical outcome. Moreover, there is evidence that early selective surfactant administration given to newborns requiring assisted ventilation leads to better outcomes. A pilot study in 40 neonates with MAS, which evaluated surfactant (beractant) instilled every $6 \mathrm{~h}$ compared with control, found that mean arterial-to-alveolar partial pressure of oxygen ratio values increased modestly after the first dose of surfactant and that oxygenation improved significantly and cumulatively after the second and third doses of surfactant. ${ }^{32}$ Although not the primary outcome, there was also a significant reduction in the need for ECMO and duration of oxygen therapy and hospitalization with surfactant therapy $(P<0.05$ for each).

A large multicenter trial compared surfactant (beractant) $(n=167)$ versus control $(n=161)$ in neonates (gestational age $\geqslant 36$ weeks) with HRF prior to ECMO treatment. ${ }^{33}$ Neonates were stratified by diagnosis (PPHN, sepsis, or MAS) and OI (15 to 22, 23 to 30,31 to 39 ), as a surrogate for severity or stage of disease. This trial reported an approximate $10 \%$ absolute reduction in ECMO rate in the surfactant-treated group $(P=0.038)$, with the principal

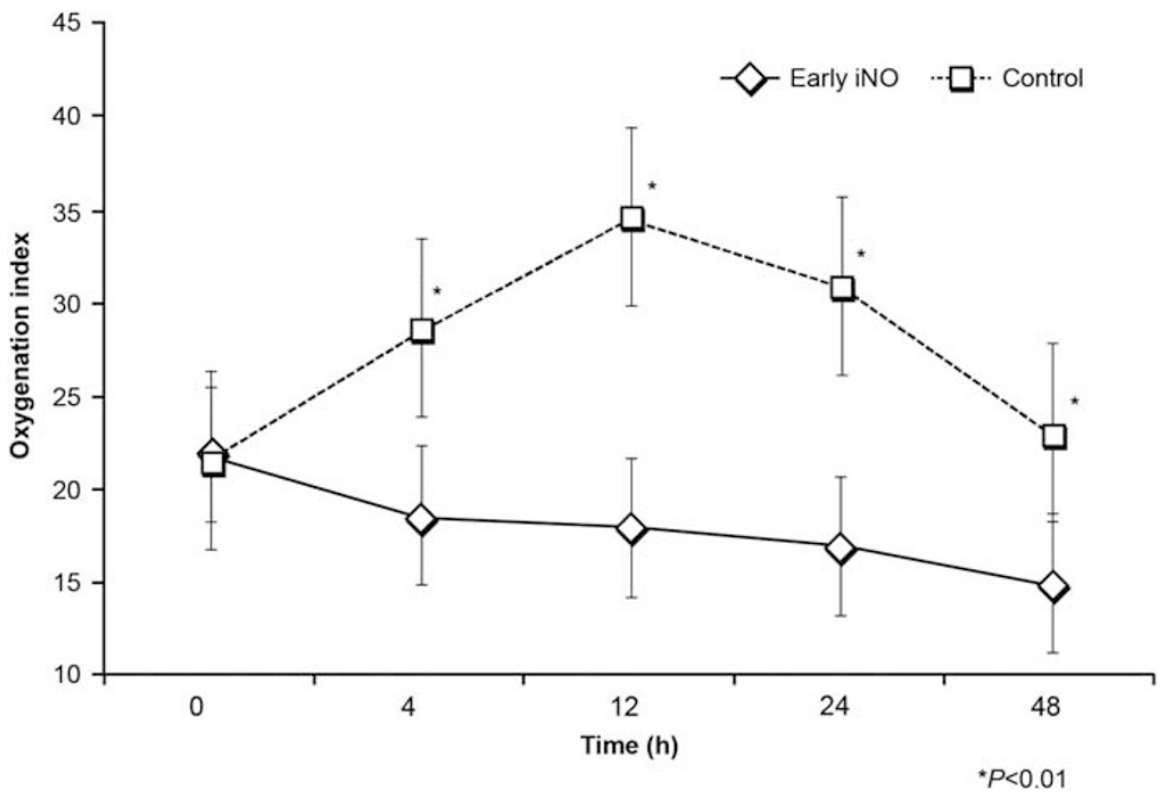

Figure 5. Change in oxygenation index $(\mathrm{OI})$ over time in newborns with moderate respiratory failure (OI between 10 and 30$)$ randomized before $48 \mathrm{~h}$ postdelivery to early treatment with 20 p.p.m. inhaled nitric oxide (iNO; early iNO group, $n=28$ ) or conventional mechanical ventilation with fraction of inspired oxygen $\left(\mathrm{FiO}_{2}\right)$ of 1.0 (control group, $\left.n=28\right)$. Points represent mean \pm s.e.m. The Ols were significantly higher after baseline in the control group $(P<0.01)$. This figure was used with permission from Gonzalez et al. ${ }^{28}$ Adapted by permission from Macmillan Publishers: J Perinatol 2010;30:420-424. 
effect in the lowest Ol stratum. Neonates enrolled late in the course of HRF (OI 31 to 39) experienced no benefit and those with a moderate degree of respiratory failure (OI 23 to 30 ) had a modest reduction in ECMO rate. In contrast, there was a highly significant $(P=0.013)$ threefold reduction in the ECMO rate when surfactant was administered in less severe or early disease (OI 15 to 22 ).

Although the use of iNO and surfactant in the management of HRF and PPHN has been well documented through clinical trials, other potential treatment approaches, including those that follow, are under active consideration based on their potential physiological effects.

\section{Prostacyclin vasodilators}

Prostacyclin $\left(\mathrm{PGI}_{2}\right)$ mediates vasodilation by activating adenylate cyclase and increasing cyclic adenosine monophosphate (cAMP) in the PASMC. The use of inhaled $\mathrm{PGI}_{2}$ (epoprostenol) is well established for acute adult pulmonary hypertension and has been described in a case series of term neonates with HRF and PPHN refractory to iNO. ${ }^{34}$ Oxygenation rapidly improved after inhalation of $\mathrm{PGI}_{2}$ in all four neonates, although the condition of one neonate subsequently deteriorated owing to alveolar capillary dysplasia. The authors speculated that neonates with PPHN and inadequate response to iNO may have impaired cGMP-mediated pulmonary vasodilation and might benefit from $\mathrm{PGI}_{2}$, which acts through cAMP (Figure 4). Successful use of inhaled lloprost, a $\mathrm{PGI}_{2}$ analog, has also been reported in combination with iNO for intractable PPHN. ${ }^{35,36}$ Although a synergistic effect with iNO has been suggested based on translational studies, there are no randomized controlled trials evaluating the effect of $\mathrm{PGI}_{2}$ vasodilators in term and late preterm neonates.

\section{SYSTEMIC AGENTS: INOTROPES, VASODILATORS, AND 'INODILATORS'}

Dopamine

Dopamine is commonly used to increase systemic blood pressure to reduce right-to-left shunting in neonates with high pulmonary arterial pressure. The effect of dopamine on systemic arterial pressure and pulmonary arterial pressure has been studied in newborn lambs with PPHN and control twins with normal pulmonary vasculature. ${ }^{37,38}$ In control lambs, systemic blood pressure was higher than pulmonary arterial pressure and increased relatively selectively in response to low doses of dopamine. In contrast, both systemic and pulmonary blood pressure were similar in PPHN lambs and increased in parallel suggesting that remodeled pulmonary arteries might have higher sensitivity to dopamine. These studies indicate that dopamine is not selective to the systemic circulation in the setting of remodeled pulmonary arteries and suggest the need for frequent echocardiography to evaluate pulmonary arterial pressure in patients with PPHN receiving dopamine therapy (especially at doses $>10 \mathrm{mcg} / \mathrm{kg} / \mathrm{min}$ ).

\section{Milrinone}

Infants with HRF and PPHN typically have right-to-left shunting, but left-to-right shunting at the atrial level can occur in the presence of left ventricular dysfunction and/or hypoplasia owing to increased left atrial pressure. ${ }^{37}$ Milrinone may have a role in improving left ventricular function and reducing pulmonary venous hypertension as it inhibits PDE-3A in both cardiomyocytes and pulmonary arterial smooth muscle cells, thereby increasing the level of CAMP resulting in improved ventricular diastolic function as well as pulmonary vasodilation (Figure 4). In newborn lambs with PPHN, intravenous milrinone reduced PVR by $22 \%$ and increased pulmonary blood flow by $18 \%{ }^{39}$
Milrinone and iNO may act synergistically as they signal through separate pathways (cAMP and CGMP, respectively), yet both interact with PDE-3A. A study in rat PASMCs showed that the NO-donor, S-nitrosoglutathione, modulates PDE-3A gene expression via mechanisms dependent upon cGMP synthesis and gene transcription. ${ }^{40}$ Consistent with a synergistic interaction, the vasodilatory effects of milrinone were found to be most pronounced in vessels from lambs with the highest PDE-3 activity, such as lambs ventilated for $24 \mathrm{~h}$ with $100 \%$ oxygen plus 20 p.p.m. iNO. $^{41}$ From a clinical perspective, case series have described the effectiveness of milrinone in improving oxygenation in term and late preterm neonates with iNO-resistant PPHN. ${ }^{42,43}$ Together, these findings suggest that milrinone may be a unique agent with optimal benefit when used in conjunction with iNO or in patients with prior NO exposure, especially in the presence of ventricular dysfunction.

\section{PDE-5 inhibitors}

Both oral and intravenous sildenafil, a PDE-5 inhibitor, have been studied in term and late preterm neonates with PPHN and found to improve oxygenation and survival. ${ }^{44,45}$ In a dose-response study, intravenous sildenafil improved oxygenation in neonates with and without concurrent iNO treatment, ${ }^{45}$ suggesting a role for sildenafil in patients with partial or poorly sustained responses to iNO. Hypothetically, sildenafil may also be effective in neonates with PPHN following prolonged hyperoxic ventilation, as PDE-5 expression and activity are increased following ventilation with high concentrations of oxygen and exposure to ROS (Figure 4). ${ }^{19}$ The availability of sildenafil as an enteral preparation makes it feasible for long-term therapy for infants with chronic lung disease. ${ }^{46,47} \mathrm{~A}$ multicenter, randomized clinical trial is underway to test the efficacy of sildenafil in iNO-resistant PPHN (NCT01720524). ${ }^{48}$

\section{ET-1 inhibitors}

Endothelin-1 (ET-1) is synthesized by vascular endothelial cells and is a potent vasoconstrictor that acts through two receptors $\left(E T_{A}\right.$ and $\mathrm{ET}_{\mathrm{B}}$ ) mediated by endothelium-derived NO. The nonspecific ET-1 receptor blocker, bosentan, has been principally used to treat pulmonary hypertension in adults. A placebo-controlled trial $(N=47)$ conducted in a single center without access to iNO or ECMO demonstrated that bosentan was more effective than placebo in improving oxygenation and well tolerated in term and late preterm neonates with PPHN. ${ }^{49}$ A recent multicenter trial $(N=21)$ among neonates with persistent respiratory failure despite iNO treatment did not demonstrate improved outcome versus placebo, possibly owing to higher baseline $\mathrm{OI}^{50}$

\section{Glucocorticoids}

Glucocorticoids have potent anti-inflammatory properties and have been shown to reduce the duration of oxygen dependence in neonates with MAS. ${ }^{51}$ There is anecdotal evidence that hydrocortisone improves oxygenation in neonates with PPHN, and it is used in some centers as a rescue strategy prior to ECMO. Recent evidence derived from animal models of PPHN suggests a potential role for glucocorticoids in restoring normal pulmonary vascular function. In a neonatal lamb model of PPHN, hydrocortisone significantly improved arterial-to-alveolar ratios and attenuated oxidative stress, in part by increasing superoxide dismutase activity. ${ }^{52}$ Hydrocortisone increased cGMP by normalizing soluble guanylyl cyclase and PDE-5 activity and by attenuating abnormalities induced by oxidative stress. Generally favorable results from studies have indicated that glucocorticoids may be beneficial, particularly in severe MAS in the presence of lung edema, pulmonary vasoconstriction and inflammation. ${ }^{53}$ 
Caution must be exercised when considering hydrocortisone therapy, as it could mask the signs of infection.

The nature of vascular dysfunction that underlies a lack of response to iNO therapy has become the subject of intense investigation. ${ }^{30}$ A number of alterations in endothelial and smooth muscle cell function in PPHN contribute to impaired vasodilation and vascular remodeling. As previously described, these alterations include increased oxidative stress, increased PDE-5 activity, decreased levels of $\mathrm{NO}$ and $\mathrm{PGl}_{2}$ and increased ET- 1 release. These changes also lead to impaired angiogenesis, which contributes to increased PVR. These studies support the use of iNO as well as PDE inhibitors, inhaled or intravenous $\mathrm{PGI}_{2}$ analogs, ET-1 antagonists and antioxidants. In addition, recent studies in the ductal ligation model identified dysfunction of endothelial AMP-activated protein kinase and peroxisome proliferator-activated receptor- $\gamma$ and depletion of tetrahydrobiopterin as important contributors to impaired angiogenesis in this model. ${ }^{54,55}$ The potential use of AMP-activated protein kinase agonists (for example, metformin), peroxisome proliferator-activated receptor- $\gamma$ agonists (for example, rosiglitazone) or tetrahydrobiopterin analogs (sepiapterin) to restore angiogenesis requires further investigation.

\section{CONCLUSION}

In summary, greater insights into the neonatal pulmonary circulation and underlying pathophysiology of HRF and PPHN have improved the treatment protocols and allowed adoption of more effective interventions for PPHN. In the current treatment era, oxygen should be considered a drug and administered accordingly. Avoiding hyperoxia is as important as avoiding hypoxia in the management of HRF. There is also evidence that surfactant and iNO use at a lower acuity of illness may reduce the progression of HRF-an approach that could improve outcomes. ${ }^{31}$ Understanding the abnormalities in the signaling pathways in PPHN helps to optimize management of this condition through the most appropriate choice and integration of therapies. For example, milrinone may be particularly beneficial following prolonged exposure to iNO plus oxygen because it inhibits PDE-3A, whereas hydrocortisone and sildenafil might be appropriate options in the settings of hyperoxia and oxidative stress owing to their effects on PDE-5 activity and expression.

Despite the progress in the management of HRF and PPHN, several issues remain to be explored. These include the integration of NO and other therapies, use of iNO prior to ventilator-induced hyperoxia and barotrauma and defining alternate outcomes. Noninvasive strategies are needed to recognize ROS formation or lung injury in a timely manner. The effect of iNO on long-term outcomes also requires further investigation. Finally, defining future clinical trials in HRF and identifying meaningful and achievable study outcomes remain important goals.

\section{CONFLICT OF INTEREST}

$\mathrm{SL}$, GGK and RHS received honoraria for their participation in a roundtable meeting supported by a grant from Mallinckrodt Pharmaceuticals, formerly lkaria. SL was a member of the speaker's bureau for Ikaria from June 2010 to October 2014 and has received grant support from the American Academy of Pediatrics and Canadian Pediatric Society. GGK has received consulting fees from Boston Health Economics and Actelion Clinical Research and lecture fees from Quintiles. RHS has received research grant support from Pfizer. NIH Grants: 5R01HD072929-03 (to SL); 5R01HL057268-11 (to GGK); 5R01HL054705-13 (to RHS).

\section{ACKNOWLEDGEMENTS}

This work is based on discussions at a roundtable meeting supported by a grant from Mallinckrodt Pharmaceuticals, formerly Ikaria. Presentations and discussions were developed solely by the participants, without grantor input. The meeting chair (RHS) determined the agenda and attendees. SL, GGK and RHS developed the presentations and led the discussions upon which this article is based, provided critical review and revisions to the outline and manuscript drafts, provided final approval of the version to be published and are accountable for the integrity of the content and for addressing questions. We thank the contributions of the following individuals who participated in discussion that shaped the content of this article: Namasivayam Ambalavanan, MD, Judy L Aschner, MD, Jason Gien, MD, John Kinsella, MD and Ola Didrik Saugstad, MD, PhD, FRCPE. Writing and editorial assistance was provided by John Kross, and Sharon Suntag and Julie Gerke of Quintiles.

\section{REFERENCES}

1 Clark RH. The epidemiology of respiratory failure in neonates born at an estimated gestational age of 34 weeks or more. J Perinatol 2005; 25: 251-257.

2 Walsh-Sukys MC, Tyson JE, Wright LL, Bauer CR, Korones SB, Stevenson DK et al. Persistent pulmonary hypertension of the newborn in the era before nitric oxide: practice variation and outcomes. Pediatrics 2000; 105: 14-20.

3 Konduri GG, Kim UO. Advances in the diagnosis and management of persistent pulmonary hypertension of the newborn. Pediatr Clin North Am 2009; 56: 579-600.

4 Nair J, Lakshminrusimha S. Update on PPHN: mechanisms and treatment. Semin Perinatol 2014; 38: 78-91.

5 Steinhorn RH. Diagnosis and treatment of pulmonary hypertension in infancy. Early Hum Dev 2013; 89: 865-874.

6 Lakshminrusimha S, Russell JA, Steinhorn RH, Swartz DD, Ryan RM, Gugino SF et al. Pulmonary hemodynamics in neonatal lambs resuscitated with $21 \%, 50 \%$, and $100 \%$ oxygen. Pediatr Res 2007; 62: 313-318.

7 Lakshminrusimha S, Swartz DD, Gugino SF, Ma CX, Wynn KA, Ryan RM et al. Oxygen concentration and pulmonary hemodynamics in newborn lambs with pulmonary hypertension. Pediatr Res 2009; 66: 539-544.

8 Lakshminrusimha S, Steinhorn RH, Wedgwood S, Savorgnan F, Nair J, Mathew B et al. Pulmonary hemodynamics and vascular reactivity in asphyxiated term lambs resuscitated with 21 and 100\% oxygen. J Appl Physiol (1985) 2011; 111: 1441-1447.

9 Perlman JM, Wyllie J, Kattwinkel J, Atkins DL, Chameides L, Goldsmith JP et al. Part 11: Neonatal resuscitation: 2010 International Consensus on Cardiopulmonary Resuscitation and Emergency Cardiovascular Care Science With Treatment Recommendations. Circulation 2010; 122: S516-S538.

10 Kattwinkel J, Perlman JM, Aziz K, Colby C, Fairchild K, Gallagher J et al. Part 15: Neonatal resuscitation: 2010 American Heart Association Guidelines for Cardiopulmonary Resuscitation and Emergency Cardiovascular Care. Circulation 2010; 122: S909-S919.

11 Moudgil R, Michelakis ED, Archer SL. Hypoxic pulmonary vasoconstriction. J Appl Physiol (1985) 2005; 98: 390-403.

12 Rudolph AM, Yuan S. Response of the pulmonary vasculature to hypoxia and $\mathrm{H}+$ ion concentration changes. J Clin Invest 1966; 45: 399-411.

13 Sanderud J, Norstein J, Saugstad OD. Reactive oxygen metabolites produce pulmonary vasoconstriction in young pigs. Pediatr Res 1991; 29: 543-547.

14 Sanderud J, Bjoro K, Saugstad OD. Oxygen radicals stimulate thromboxane and prostacyclin synthesis and induce vasoconstriction in pig lungs. Scand J Clin Lab Invest 1993; 53: 447-455.

15 Lakshminrusimha S, Russell JA, Wedgwood S, Gugino SF, Kazzaz JA, Davis JM et al. Superoxide dismutase improves oxygenation and reduces oxidation in neonatal pulmonary hypertension. Am J Respir Crit Care Med 2006; 174: 1370-1377.

16 Belik J, Jankov RP, Pan J, Yi M, Chaudhry I, Tanswell AK. Chronic O2 exposure in the newborn rat results in decreased pulmonary arterial nitric oxide release and altered smooth muscle response to isoprostane. J Appl Physiol (1985) 2004; 96: 725-730.

17 Faraci FM, Didion SP. Vascular protection: superoxide dismutase isoforms in the vessel wall. Arterioscler Thromb Vasc Biol 2004; 24: 1367-1373.

18 Lakshminrusimha S, Russell JA, Steinhorn RH, Ryan RM, Gugino SF, Morin FC III et al. Pulmonary arterial contractility in neonatal lambs increases with $100 \%$ oxygen resuscitation. Pediatr Res 2006; 59: 137-141.

19 Farrow KN, Groh BS, Schumacker PT, Lakshminrusimha S, Czech L, Gugino SF et al. Hyperoxia increases phosphodiesterase 5 expression and activity in ovine fetal pulmonary artery smooth muscle cells. Circ Res 2008; 102: 226-233.

20 Sanderud J, Oroszlan G, Bjoro K, Kumlin M, Saugstad OD. D-penicillamine inhibits the action of reactive oxygen species in the pig pulmonary circulation. $J$ Perinat Med 1995; 23: 385-393.

21 Steinhorn RH, Albert G, Swartz DD, Russell JA, Levine CR, Davis JM. Recombinant human superoxide dismutase enhances the effect of inhaled nitric oxide in persistent pulmonary hypertension. Am J Respir Crit Care Med 2001; 164: 834-839.

22 Afolayan AJ, Teng RJ, Eis A, Mickalkiewicz T, Konduri GG. Decreased nitric oxide (NO) levels contribute to impaired mitochondrial biogenesis and oxidative stress in fetal lambs with persistent pulmonary hypertension (PPHN). Abstract presented at the Pediatric Academic Societies (PAS) Annual Meeting; 26 April 2015; San Diego, CA, USA. Abstract 2785.2. 
23 Afolayan AJ, Eis A, Alexander M, Michalkiewicz T, Teng RJ, Lakshminrusimha S et al. Decreased endothelial NOS expression and function contributes to impaired mitochondrial biogenesis and oxidative stress in fetal lambs with PPHN. Am J Physiol Lung Cell Mol Physiol 2015; 310(1): L40-L49.

24 Roberts JD Jr., Fineman JR, Morin FC III, Shaul PW, Rimar S, Schreiber MD et al. Inhaled nitric oxide and persistent pulmonary hypertension of the newborn. The Inhaled Nitric Oxide Study Group. N Engl J Med 1997; 336: 605-610.

25 Inhaled nitric oxide and hypoxic respiratory failure in infants with congenital diaphragmatic hernia. The Neonatal Inhaled Nitric Oxide Study Group (NINOS). Pediatrics 1997; 99: 838-845.

26 Clark RH, Kueser TJ, Walker MW, Southgate WM, Huckaby JL, Perez JA et al. Lowdose nitric oxide therapy for persistent pulmonary hypertension of the newborn. Clinical Inhaled Nitric Oxide Research Group. N Engl J Med 2000; 342: 469-474.

27 Early compared with delayed inhaled nitric oxide in moderately hypoxaemic neonates with respiratory failure: a randomised controlled trial. The FrancoBelgium Collaborative NO Trial Group. Lancet 1999; 354: 1066-1071.

28 Gonzalez A, Fabres J, D'Apremont I, Urcelay G, Avaca M, Gandolfi C et al. Randomized controlled trial of early compared with delayed use of inhaled nitric oxide in newborns with a moderate respiratory failure and pulmonary hypertension. J Perinatol 2010; 30: 420-424.

29 Konduri GG, Solimano A, Sokol GM, Singer J, Ehrenkranz RA, Singhal N et al. A randomized trial of early versus standard inhaled nitric oxide therapy in term and near-term newborn infants with hypoxic respiratory failure. Pediatrics 2004; 113 : 559-564.

30 Konduri GG, Sokol GM, Van Meurs KP, Singer J, Ambalavanan N, Lee T et al. Impact of early surfactant and inhaled nitric oxide therapies on outcomes in term/late preterm neonates with moderate hypoxic respiratory failure. J Perinatol 2013; 33: 944-949.

31 Konduri GG, Menzin J, Frean M, Lee T, Potenziano J, Singer J. Inhaled nitric oxide in term/late preterm neonates with hypoxic respiratory failure: estimating the financial impact of earlier use. J Med Econ 2015; e-pub ahead of print.

32 Findlay RD, Taeusch HW, Walther FJ. Surfactant replacement therapy for meconium aspiration syndrome. Pediatrics 1996; 97: 48-52.

33 Lotze A, Mitchell BR, Bulas DI, Zola EM, Shalwitz RA, Gunkel JH. Multicenter study of surfactant (beractant) use in the treatment of term infants with severe respiratory failure. Survanta in Term Infants Study Group. J Pediatr 1998; 132: 40-47.

34 Kelly LK, Porta NF, Goodman DM, Carroll CL, Steinhorn RH. Inhaled prostacyclin for term infants with persistent pulmonary hypertension refractory to inhaled nitric oxide. J Pediatr 2002; 141: 830-832.

35 Ehlen M, Wiebe B. lloprost in persistent pulmonary hypertension of the newborn Cardiol Young 2003; 13: 361-363.

36 Kahveci H, Yilmaz O, Avsar UZ, Ciftel M, Kilic O, Laloglu F et al. Oral sildenafil and inhaled iloprost in the treatment of pulmonary hypertension of the newborn. Pediatr Pulmonol 2014; 49: 1205-1213.

37 Lakshminrusimha $\mathrm{S}$. The pulmonary circulation in neonatal respiratory failure. Clin Perinatol 2012; 39: 655-683.

38 Kirmani Kl, Ryan RM, Morin FC et al. Effect of dopamine on pulmonary and systemic pressures in control and PPHN neonatal lambs. Abstract presented at the Pediatric Academic Societies (PAS) Meeting; 38 May 2007; Toronto, ON, Canada. Abstract 6291.20.

39 Rashid N, Morin FC III, Swartz DD, Ryan RM, Wynn KA, Wang H et al. Effects of prostacyclin and milrinone on pulmonary hemodynamics in newborn lambs with persistent pulmonary hypertension induced by ductal ligation. Pediatr Res 2006; 60: 624-629.

40 Busch CJ, Graveline AR, Jiramongkolchai K, Liu H, Sanchez LS, Bloch KD. Phosphodiesterase $3 \mathrm{~A}$ expression is modulated by nitric oxide in rat pulmonary artery smooth muscle cells. J Physiol Pharmacol 2010; 61: 663-669.

41 Chen B, Lakshminrusimha S, Czech L, Groh BS, Gugino SF, Russell JA et al. Regulation of phosphodiesterase 3 in the pulmonary arteries during the perinatal period in sheep. Pediatr Res 2009; 66: 682-687.

42 Bassler D, Choong K, McNamara P, Kirpalani H. Neonatal persistent pulmonary hypertension treated with milrinone: four case reports. Biol Neonate 2006; 89: 1-5.

43 McNamara PJ, Laique F, Muang-In S, Whyte HE. Milrinone improves oxygenation in neonates with severe persistent pulmonary hypertension of the newborn. J Crit Care 2006; 21: 217-222.

44 Baquero $H$, Soliz A, Neira F, Venegas ME, Sola A. Oral sildenafil in infants with persistent pulmonary hypertension of the newborn: a pilot randomized blinded study. Pediatrics 2006; 117: 1077-1083.

45 Steinhorn RH, Kinsella JP, Pierce C, Butrous G, Dilleen M, Oakes M et al. Intravenous sildenafil in the treatment of neonates with persistent pulmonary hypertension. J Pediatr 2009; 155: 841-847.

46 Farrow KN, Steinhorn RH. Sildenafil therapy for bronchopulmonary dysplasia: not quite yet. J Perinatol 2012; 32: 1-3.

47 Mourani PM, Sontag MK, Ivy DD, Abman SH. Effects of long-term sildenafil treatment for pulmonary hypertension in infants with chronic lung disease. J Pediatr 2009; 154: 379-384.

48 Clinicaltrials.gov Web site. A study to evaluate safety and efficacy of IV sildenafil in the treatment of neonates with persistent pulmonary hypertension of the newborn. www.clinicaltrials.gov. 2015.

49 Mohamed WA, Ismail M. A randomized, double-blind, placebo-controlled, prospective study of bosentan for the treatment of persistent pulmonary hypertension of the newborn. J Perinatol 2012; 32: 608-613.

50 Steinhorn RH, Kusic-Pajic A, Cornelisse P, Fineman JR, Gehin M, Nowbakht P et al. Bosentan as adjunctive therapy for persistent pulmonary hypertension of the newborn: Results of the FUTURE-4 Study. Circulation 2014; 130: A13503.

51 Tripathi S, Saili A. The effect of steroids on the clinical course and outcome of neonates with meconium aspiration syndrome. J Trop Pediatr 2007; 53: 8-12.

52 Perez M, Lakshminrusimha S, Wedgwood S, Czech L, Gugino SF, Russell JA et al. Hydrocortisone normalizes oxygenation and CGMP regulation in lambs with persistent pulmonary hypertension of the newborn. Am J Physiol Lung Cell Mol Physiol 2012; 302: L595-L603.

53 Mokra D, Mokry J. Glucocorticoids in the treatment of neonatal meconium aspiration syndrome. Eur J Pediatr 2011; 170: 1495-1505.

54 Teng RJ, Du J, Afolayan AJ, Eis A, Shi Y, Konduri GG. AMP kinase activation improves angiogenesis in pulmonary artery endothelial cells with in utero pulmonary hypertension. Am J Physiol Lung Cell Mol Physiol 2013; 304: L29-L42.

55 Armitage P. Sequential Medical Trials. 2nd edn. John Wiley \& Sons: New York, USA, 1975. 